\title{
Does Gender Impact Business Students' Perceptions Of Teaching Effectiveness?
}

Leon Korte, Ph.D., University of South Dakota, USA

Angeline Lavin, Ph.D., University of South Dakota, USA

Thomas Davies, L.L.M., University of South Dakota, USA

\begin{abstract}
While there are certainly differences of opinion regarding teaching effectiveness, the goal of this study is to investigate whether there is consistency or differences in opinion based on the gender of the student doing the evaluation of the instructor or the gender of the instructor being evaluated. This paper summarizes the gender-based findings from a survey administered to students in fall 2011 at a mid-sized Association to Advance Collegiate Schools of Business International (AACSB International) accredited Midwestern university business school. Thirtyfive traits were presented for evaluation. The findings of this study suggest that there are differences between female and male student ratings of teacher effectiveness. Females in general tend to rate teachers higher overall in terms of teaching effectiveness. Furthermore, there are specific traits that appear to be more important to females, and other specific traits which appear to be more important to males. This study provides strong evidence that there are systematic differences between male and female students in terms of their perceptions of the teaching traits they find important and how they rate instructors of each gender. It is important that faculty members and especially administrators are aware of the potential for gender bias in ratings of teacher effectiveness. Men and women have different perceptions. Male and female students are different, and they perceive differences between male and female faculty members.
\end{abstract}

Keywords: Student Perceptions; Teaching Effectiveness; Teacher Characteristics; Gender

\section{INTRODUCTION}

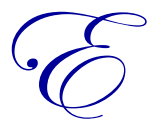

xperienced instructors know that "teaching" is a constantly evolving process. There is not a singular definition of good teaching nor is there just one description of an effective instructor. What traits make someone good at his or her vocation will not be the same for everyone, and may not only depend on the gender of subject in question, but also the gender of the one doing the evaluation. Many research studies over the past 20 years have found evidence that suggests that male and female students have different perceptions of teaching effectiveness. We (Lavin, Korte, \& Davies, 2012) found that when business students were asked to rank the contribution to teaching effectiveness of 35 different traits, the average unadjusted response of female students was greater than the average response of male students for 29 of the 35 identified traits, and for 15 out of the 29, the differences were statistically significant at the 5\% level. The 15 teaching-related characteristics that females rated statistically higher than males in the sample included professionalism, timely feedback, class preparedness, organized presentation, responsiveness, professional attire, high academic standards, out of class accessibility, respectful, enthusiastic, clear presentations, concise explanations, encouraging, fair, and engaging. Based on these earlier findings, this current inquiry was initiated to provide additional insight into differences in expectations between male and female business students. For example, the underlying behaviors or standards that male students associate with "high academic standards" or "professionalism" may differ from those that female students associate with the same traits.

While there are certainly differences of opinion regarding teaching effectiveness, the goal of this study is to investigate whether there is consistency or differences in opinion based on the gender of the student doing the evaluation of the instructor or the gender of the instructor. In other words, are there systematic differences between 
male and female business students in terms of what teaching traits each finds important independent of instructor gender? Furthermore, are their similarities and differences between how male versus female instructors are rated? Specifically, this paper summarizes the gender-based findings from a survey administered to just under 400 students in select business school classes in fall 2011 at a mid-sized AACSB International accredited Midwestern university business school. While student gender is certainly not something that a teacher can control or likely even influence in terms of specific course enrollment, the impact (if any) of student gender with respect to their opinions of teacher effectiveness will facilitate additional discussion about teaching effectiveness. Further, this study can be especially important to instructors of courses dominated by students of one gender, as is sometimes the case in business classes, at least to the extent that some of the identified traits can be managed through their behavior.

\section{PRIOR RESEARCH}

A number of studies in the past have looked at whether the gender of the student biases faculty ratings as reflected on student evaluations, and a number of research projects have examined the notion of "in group bias," that is, whether female students prefer female teachers and male students prefer male teachers. The purpose of this research is not to determine whether biases exist but rather to study the association between student gender and the importance of certain faculty traits. The goal is to determine whether male and female students believe that different traits impact teacher effectiveness, and whether those traits differ by gender of the instructor. Recent studies suggest that there may be certain personality traits and classroom behaviors that are preferred by students based on their gender.

Bachen, McLoughlin, and Garcia (1999) surveyed nearly 500 university students about their perceptions of male and female faculty. Female students rated female faculty especially high across five teaching dimensions (caring/expressive, interactive/varied, professional/challenge, organized, and easy-going), but rated the male faculty comparatively lower on all of them. On the other hand, male students did not evaluate male and female professors as being significantly different on any of the five teaching dimensions. Female students rated female faculty especially high on the caring-expressive dimension, which includes understanding and approachability. Basow (2000) found that female students tend to rate female faculty higher than male faculty, while male students tend to rate male faculty higher than female faculty. Zhang (2004) concluded that it is often students' personal biases, rather than instructor performance, that have the greatest impact on perceptions of teaching effectiveness. Student biases are shaped by a variety of factors including but not limited to their own age, gender, major, learning style, and locus of control. Sprinkle's 2008 results are consistent with this conclusion that personal biases strongly influence student perceptions of professor/instructor effectiveness. In fact, Sprinkle (2008) statistically shows the existence of several pronounced student-held biases including the fact that female students prefer female professors/instructors while male students prefer male teachers. Taken together, there is a significant amount of evidence that same gender identification occurs and results in a gender bias on behalf of student raters. Therefore, as McKeachie suggested in 1990, at least perceived effective teaching is dependent on the characteristics of the students themselves in addition to the teacher's behavior and knowledge.

In the second of Feldman's (1993) two-part review of students' perceptions of male and female college teachers, prior research of student evaluations of actual professors was aggregated and analyzed. Results of the compiled studies indicated that female students have a tendency toward rating female professors higher. The rating was statistically significant but so slight as to be practically negligible. Feldman also analyzed the data controlling for various aspects such as academic discipline, student gender, and academic rank of teacher. In controlling for student gender, Feldman found that students tended to rank professors of the same gender higher. However, the study was unable to determine how much is due to different types of classes or because of different student preferences.

Basow (1995) compiled instructor evaluation surveys given over a period of 4 years at a large northeastern university. The research found that male instructors are rated similarly by both male and female students. Female instructors are rated differently, however, with female students rating more positively than male students. Consistent with other findings, female instructors were rated higher on sensitivity, student comfort, and respect. Also, male students frequently rated female professors the lowest on fairness, thought stimulation, and nonrepetition. While statistically significant, the gender differences explained a very low percentage of the variances, with the most significant predictor being students' expected grade. 
Fernandez and Mateo (1997) selected a sample of over 1,000 student evaluation surveys administered at a university in Madrid, Spain to study the effect, if any, of student and faculty gender on student evaluations of instructor quality. The results primarily aligned with their hypothesis that gender has little to no effect on overall student evaluations. However, they did find evidence that female students, in general, tended to give higher ratings than their male peers. There was also statistical significance when considering evaluations by academic discipline, but again, it was so small as to be practically negligible.

Centra and Gaubatz (2000) surveyed students in 741 classes to evaluate student perceptions of instructor effectiveness. When the student ratings were averaged by gender within each class, female instructors tended to receive higher ratings by female students, yet male instructors' ratings were essentially the same regardless of who completed the evaluation. The scale that rated students' perception of the overall learning outcome of the class showed no differences based on student gender. The results of the component of the experiment that compared male and female instructors' evaluations across classes did show some consistent differences between male and female students' instructor ratings. Female students rated female instructors higher than male students on faculty/student interaction and assignments, exams, and grading. However, male students rated male instructors higher on course organization and planning. When considering academic discipline, both male and female students tended to give female instructors higher ratings in the natural sciences on a few scales. This slight bias was also noticeable for the business and social science disciplines. The authors of the study believed this could be reflective of different preferred teaching styles, as in this study, female instructors were more likely than male instructors to use discussion, rather than traditional lecture.

It is interesting to note that gender expectations may play a role in student evaluation of teaching effectiveness. Sprague and Massoni (2005) argued that gender expectations permeate society, and, therefore, are likely to shape the roles that male and female professors assume in the classroom. They cite prior research findings as evidence that students' evaluations of male and female professors are based on different sets of standards for each gender. Their study surveyed 288 students asking them to list four adjectives of each of their worst and best professors. Looking at the "best" teacher adjectives, words such as smart, helpful, and enthusiastic were cited at about the same rate for both male and female teachers. However, men were more likely to be funny, and women to be nurturing or caring. Worst teachers were described as uncaring, boring, and rude, but males were more likely to be boring and self-centered, and females more likely to be mean, rigid, and unfair. While the differences could result from actual gender differences in teaching, Sprague and Massoni believed the differences were a result of students using gender expectations to evaluate their teachers.

Tatro (1995) surveyed 537 university students about teacher effectiveness. Students were requested to answer 11 questions on a Likert scale taken from a standardized teacher evaluation form. Eight male and eight female instructors in a diverse range of fields distributed the questionnaire. Analysis showed that female instructors received higher ratings than males, and female students gave higher ratings than male students. However, this finding did not hold when students' expected grade, which was found to significantly affect ratings, was included as a factor. Tatro indicated that, in light of these results, when using student evaluation forms for personnel decisions, classroom composition and instructor gender must be considered.

Young, Rush, and Shaw (2009) studied how male and female students (both undergraduate and graduate) rated their male and female instructors on three factors related to effective teaching. The three factors were interpersonal characteristics, pedagogical characteristics, and course content characteristics. Their results yielded gender-specific differences in ratings as well as in gender bias. Specifically, the results showed that female students rated female instructors significantly higher on pedagogical characteristics and course content characteristics than they rated male instructors. Similarly, male students rated male instructors significantly higher on the same two factors. Interpersonal characteristics of male and female instructors were not rated differently by the male and female students.

Given the results of the prior research, there appears to be evidence to support the idea that male and female respondents may have differing opinions on what traits equate with effective teaching. Therefore, the goal of this work is to add another perspective to the discussion and to look for evidence of consistent differences between male and female students in terms of the traits they perceive in effective teachers. The goal is to begin to identify what female and male students value in effective teachers. 


\section{PRESENT STUDY}

Students from a cross-section of undergraduate and graduate business face-to-face classes at a mid-sized AACSB International accredited Midwestern university business school were given the opportunity to participate in a research study by completing a brief, two-page questionnaire, the purpose of which was to assess student perceptions of the characteristics and traits that contribute to good teaching. The survey instrument consisted of a list of 35 instructor traits and characteristics; survey respondents were asked to indicate the extent to which each contributes, if at all, to good teaching. These traits were selected due to their inclusion in prior studies as well as our own experience. In addition, each respondent was asked to identify, from the 35 , the 5 instructor traits that he or she considered the most and least important factors in good teaching. Respondents were also asked a number of demographic questions, including whether they were graduate or undergraduate students, their program of study or major, and their year in school (e.g., freshman, sophomore) as well as their grade point average (GPA), gender, age, employment status and personality type.

The survey was administered to students in fall 2011 in seven different face-to-face classes including those at the 100 (first year), 200 (second year), 300 (junior level), 400 (senior level) and graduate (700) levels. Courses selected included a general introductory survey of business course, principles of economics, three undergraduate core business courses (i.e., classes required of all business majors), and one graduate core course each from the MBA and the MPA (Master of Professional Accountancy) programs. The courses were selected in order to achieve representation from a variety of students in the business school as well as to minimize the potential for the same student to receive the survey multiple times. Students were asked to complete the survey only once. Due to the fact that there were multiple sections of several of the courses offered on the university's main campus and in a satellite location, 19 sections in total were studied. Faculty members who participated were asked to devote class time to allow students to complete the survey due to the anticipated positive impact on the response rate.

In total, 381 respondents answered all substantive and related demographic questions; 158 participants (41.5\%) self-reported their gender as "female" and 223 students (58.5\%) self-reported their gender as "male." These percentage differences are reflective of the business school's current student population. Interestingly, the USD School of Business had a similar proportion of male and female students in 1992, with 60\% male students and $40 \%$ female students across both undergraduate and graduate programs. These surveys serve as the basis for the analyses reported in this paper. A side-by-side comparison of the demographic characteristics of the female and male respondents is presented in Table 1 (Appendix).

\section{RESULTS}

As mentioned, survey respondents were asked to rate 35 individual traits that might be considered as contributing to good teaching. The respondents were asked to rate each trait on a scale of [3] "Major Contribution," [2] "Moderate Contribution," [1] "Minimal Contribution," and [0] "No Contribution." The null hypothesis for this analysis was "There is no expected difference in responses from female students when compared to responses from male students." A means test was used to test the hypothesis. A higher mean indicates a greater perceived contribution to teaching effectiveness. For six of the 35 traits (work/industry experience, educational credentials, established research record, experienced lecturer, sense of humor, and relaxed demeanor), the average response of female students was lower than the average response of male students. For the remaining 29 traits, the average response of female students was greater than the average response of male students. Further, with respect to these 29 traits, 15 comparisons reflected statistically significant differences at $p=0.05$; five comparisons were statistically significant at $p=0.10$; and two comparisons reflected a difference statistically significant at $p=0.20$. The 22 traits that were statistically significant are each denoted with an asterisk in Table 1 below. There were no statistically significant differences for any of the six traits in which the average response by male students was reported as greater than the average response by female students. 
Table 1

Female and Male Student Comparisons of Traits Mean Responses Based on Raw Data

\begin{tabular}{|c|c|c|c|c|c|c|c|c|c|c|c|}
\hline \multirow[b]{3}{*}{ Traits } & \multicolumn{5}{|c|}{$\begin{array}{c}\text { Student: Female } \\
\text { Instructor: Either } \\
\mathbf{N}=\mathbf{1 5 8}\end{array}$} & \multicolumn{5}{|c|}{$\begin{array}{c}\text { Student: Male } \\
\text { Instructor: Either } \\
\mathbf{N}=\mathbf{2 2 3} \\
\end{array}$} & \multirow[b]{3}{*}{ p-value } \\
\hline & \multicolumn{5}{|c|}{ Distribution } & \multicolumn{5}{|c|}{ Distribution } & \\
\hline & Mean & 3 & 2 & 1 & $\mathbf{0}$ & Mean & 3 & 2 & 1 & $\mathbf{0}$ & \\
\hline Rank/title & 1.3354 & 15 & 53 & 60 & 30 & 1.3004 & 24 & 60 & 98 & 41 & 0.706 \\
\hline Established research record & 1.5443 & 15 & 70 & 59 & 14 & 1.5561 & 21 & 104 & 76 & 22 & 0.886 \\
\hline Professional attire* & 1.6646 & 32 & 59 & 49 & 18 & 1.3946 & 39 & 57 & 80 & 47 & 0.007 \\
\hline Strict adherence to course materials* & 1.6646 & 25 & 63 & 62 & 8 & 1.5157 & 32 & 79 & 84 & 28 & 0.089 \\
\hline Rigorous & 1.7278 & 22 & 76 & 55 & 5 & 1.6323 & 33 & 85 & 95 & 10 & 0.226 \\
\hline Repetitive (content/concepts) & 1.8038 & 30 & 73 & 49 & 6 & 1.7309 & 33 & 113 & 61 & 16 & 0.376 \\
\hline Educational credentials & 1.9051 & 38 & 73 & 41 & 6 & 1.9552 & 66 & 91 & 56 & 10 & 0.559 \\
\hline Professional certification(s) & 2.0000 & 41 & 79 & 35 & 3 & 1.9596 & 59 & 101 & 58 & 5 & 0.611 \\
\hline Relaxed demeanor & 2.0823 & 49 & 78 & 26 & 5 & 2.1345 & 68 & 119 & 34 & 2 & 0.497 \\
\hline Technological proficiency & 2.1013 & 47 & 83 & 25 & 3 & 2.0583 & 61 & 120 & 36 & 6 & 0.571 \\
\hline Outgoing personality & 2.2089 & 56 & 80 & 21 & 1 & 2.1570 & 82 & 97 & 41 & 3 & 0.488 \\
\hline High academic standards* & 2.2342 & 55 & 85 & 18 & 0 & 2.0404 & 59 & 120 & 38 & 6 & 0.006 \\
\hline Experienced lecturer & 2.2532 & 67 & 67 & 21 & 3 & 2.2646 & 91 & 103 & 26 & 3 & 0.882 \\
\hline Out of class accessibility* & 2.2722 & 62 & 77 & 19 & 0 & 2.1256 & 71 & 109 & 43 & 0 & 0.039 \\
\hline Sense of Humor & 2.2785 & 68 & 67 & 22 & 1 & 2.3184 & 113 & 70 & 38 & 2 & 0.608 \\
\hline Work (industry) experience & 2.3228 & 68 & 73 & 17 & 0 & 2.3229 & 101 & 93 & 29 & 0 & 0.999 \\
\hline Structured $*$ & 2.3354 & 71 & 69 & 18 & 0 & 2.2152 & 79 & 115 & 27 & 2 & 0.088 \\
\hline Professionalism* & 2.3608 & 72 & 73 & 11 & 2 & 2.1928 & 88 & 93 & 39 & 3 & 0.023 \\
\hline Dynamic presenter & 2.3734 & 75 & 67 & 16 & 0 & 2.2915 & 91 & 107 & 24 & 1 & 0.237 \\
\hline Enthusiastic* & 2.4684 & 86 & 60 & 12 & 0 & 2.3274 & 97 & 103 & 22 & 1 & 0.037 \\
\hline Encouraging* & 2.4810 & 92 & 50 & 16 & 0 & 2.2601 & 90 & 103 & 28 & 2 & 0.002 \\
\hline Caring attitude* & 2.5127 & 95 & 49 & 14 & 0 & 2.4215 & 116 & 89 & 14 & 4 & 0.192 \\
\hline Engaging* & 2.5190 & 90 & 61 & 6 & 1 & 2.3363 & 94 & 112 & 15 & 2 & 0.004 \\
\hline Concise explanations* & 2.5253 & 90 & 61 & 7 & 0 & 2.3677 & 99 & 107 & 17 & 0 & 0.011 \\
\hline Clear presentations* & 2.5570 & 95 & 56 & 7 & 0 & 2.3767 & 102 & 104 & 16 & 1 & 0.004 \\
\hline Organized presentation* & 2.5633 & 93 & 61 & 4 & 0 & 2.3812 & 102 & 108 & 9 & 4 & 0.003 \\
\hline Timely feedback* & 2.5759 & 100 & 49 & 9 & 0 & 2.4170 & 109 & 99 & 14 & 1 & 0.013 \\
\hline Receptive to questions* & 2.5759 & 98 & 53 & 7 & 0 & 2.4619 & 113 & 102 & 6 & 2 & 0.062 \\
\hline Responsive* & 2.5949 & 98 & 56 & 4 & 0 & 2.3767 & 100 & 108 & 14 & 1 & 0.000 \\
\hline Respectful* & 2.6266 & 107 & 43 & 8 & 0 & 2.4933 & 122 & 90 & 10 & 1 & 0.030 \\
\hline Approachability* & 2.6519 & 111 & 39 & 8 & 0 & 2.5471 & 131 & 85 & 5 & 2 & 0.083 \\
\hline Fair* & 2.6646 & 115 & 34 & 8 & 1 & 2.5202 & 132 & 78 & 10 & 3 & 0.026 \\
\hline Strong communication skills* & 2.6772 & 113 & 39 & 6 & 0 & 2.5740 & 141 & 70 & 11 & 1 & 0.083 \\
\hline Class preparedness* & 2.7089 & 118 & 35 & 4 & 1 & 2.5336 & 132 & 79 & 11 & 1 & 0.003 \\
\hline Content/subject matter expertise* & 2.7532 & 122 & 33 & 3 & 0 & 2.6771 & 154 & 66 & 3 & 0 & 0.131 \\
\hline
\end{tabular}

\section{Controlling for Gender Differences}

Given the number of traits in which the average responses of one group were at a statistically significant level more frequently than the average responses of the other group, it appeared as if there might be a systematic group bias within each group. A means test of the two groups based on all responses was conducted. The first group (self-identified as female) included 5,530 responses and reflected an average score of 2.2835 with a standard deviation of 0.7685 ; the second group (self-identified as male) included 7,805 responses and reflected an average score of 2.1782 with a standard deviation of 0.7938 . The differences between the two groups was statistically significant at $p=0.0000$. A higher average suggests a greater contribution to effective teaching. The individual responses in each group were standardized by dividing the difference between the actual response and the average group response by the group standard deviation. This yielded a group mean of zero and a standard deviation of one for each group of respondents. The mean standardized responses for each group and each trait are reported in Table 2 . 
Table 2

Female and Male Student Comparisons of Traits Mean Responses Based on Standardized Data

\begin{tabular}{|c|c|c|c|c|c|}
\hline \multirow[b]{2}{*}{ Traits } & \multicolumn{2}{|c|}{$\begin{array}{l}\text { Student: Female } \\
\text { Instructor: Either } \\
\qquad \mathbf{N}=\mathbf{1 5 8}\end{array}$} & \multicolumn{2}{|c|}{$\begin{array}{c}\text { Student: Male } \\
\text { Instructor: Either } \\
\mathbf{N}=\mathbf{2 2 3} \\
\end{array}$} & \multirow[b]{2}{*}{ p-value } \\
\hline & Mean & Variance & Mean & Variance & \\
\hline Rank/title & -1.23370 & 1.35048 & -1.10582 & 1.26447 & 0.28419 \\
\hline Established research record & -0.96192 & 1.04817 & -0.78381 & 1.00839 & 0.09255 \\
\hline Professional attire & -0.80545 & 1.45833 & -0.98719 & 1.61052 & 0.15733 \\
\hline Strict adherence to course materials & -0.80545 & 1.09165 & -0.83465 & 1.25607 & 0.79439 \\
\hline Rigorous & -0.72309 & 0.91991 & -0.68777 & 0.98550 & 0.72727 \\
\hline Repetitive (content/concepts) & -0.62426 & 1.04523 & -0.56348 & 1.01416 & 0.56546 \\
\hline Educational credentials & -0.49249 & 1.09547 & -0.28102 & 1.15496 & 0.05542 \\
\hline Professional certification(s) & -0.36896 & 0.94906 & -0.27537 & 0.97684 & 0.35904 \\
\hline Relaxed demeanor* & -0.26189 & 1.01302 & -0.05504 & 0.75756 & 0.03741 \\
\hline Technological proficiency & -0.23719 & 0.88845 & -0.15108 & 0.85963 & 0.37701 \\
\hline Outgoing personality & -0.09718 & 0.79923 & -0.02679 & 0.92587 & 0.46376 \\
\hline High academic standards & -0.06424 & 0.69384 & -0.17368 & 0.86245 & 0.22925 \\
\hline Experienced lecturer & -0.03953 & 0.96926 & 0.10879 & 0.81065 & 0.13429 \\
\hline Out of class accessibility & -0.01482 & 0.74736 & -0.06634 & 0.78987 & 0.57145 \\
\hline Sense of Humor & -0.00659 & 0.88162 & 0.17658 & 0.97511 & 0.06713 \\
\hline Work (industry) experience & 0.05106 & 0.73917 & 0.18223 & 0.76320 & 0.14583 \\
\hline Structured & 0.06753 & 0.76811 & 0.04665 & 0.74114 & 0.81756 \\
\hline Professionalism & 0.10047 & 0.75964 & 0.01840 & 0.93446 & 0.38746 \\
\hline Dynamic presenter & 0.11695 & 0.74381 & 0.14269 & 0.71530 & 0.77249 \\
\hline Enthusiastic & 0.24048 & 0.68313 & 0.18788 & 0.70850 & 0.54399 \\
\hline Encouraging & 0.25695 & 0.77050 & 0.10314 & 0.79295 & 0.09476 \\
\hline Caring attitude & 0.29813 & 0.72770 & 0.30652 & 0.76050 & 0.92541 \\
\hline Engaging & 0.30637 & 0.61951 & 0.19918 & 0.65612 & 0.19651 \\
\hline Concise explanations & 0.31460 & 0.57589 & 0.23873 & 0.61374 & 0.34340 \\
\hline Clear presentations & 0.35578 & 0.57146 & 0.25002 & 0.64599 & 0.19087 \\
\hline Organized presentation & 0.36402 & 0.50545 & 0.25567 & 0.67632 & 0.17074 \\
\hline Timely feedback & 0.38049 & 0.61029 & 0.30087 & 0.63067 & 0.33099 \\
\hline Receptive to questions & 0.38049 & 0.56716 & 0.35736 & 0.56783 & 0.76799 \\
\hline Responsive & 0.40519 & 0.49692 & 0.25002 & 0.61739 & 0.04432 \\
\hline Respectful & 0.44637 & 0.57125 & 0.39691 & 0.58437 & 0.53144 \\
\hline Approachability & 0.47931 & 0.55924 & 0.46470 & 0.55231 & 0.85065 \\
\hline Fair & 0.49579 & 0.61712 & 0.43080 & 0.66959 & 0.43481 \\
\hline Strong communication skills & 0.51226 & 0.50190 & 0.49860 & 0.59001 & 0.85801 \\
\hline Class preparedness & 0.55344 & 0.50265 & 0.44775 & 0.59694 & 0.16816 \\
\hline Content/subject matter expertise & 0.61109 & 0.38149 & 0.62853 & 0.39144 & 0.78717 \\
\hline
\end{tabular}

Means tests on these standardized responses yielded only one statistically significant difference, relaxed demeanor, which male respondents scored as contributing more to good teaching than did female respondents.

\section{Female Student Responses Across Courses}

Of the 158 female students responding to the survey, 57 responded in classes taught by female instructors, and 101 responded in classes taught by male instructors. Twelve teaching traits reflected statistically significant differences when comparing female student rankings in courses taught by female instructors as compared to female student rankings in courses taught by male instructors. These traits and the mean standardized responses for each group are reported in Table 3. For only one teaching trait did female students rate female instructors higher than male instructors; female students perceived "class preparedness" as contributing more to good teaching for female instructors (mean standardized response $=0.77248$ ) than male instructors (mean standardized response $=0.42982$ ). Female students rated this as contributing more than average to good teaching in general and considered it as contributing more to good teaching for female instructors than for male instructors. 
Table 3

Female Student Comparisons of Traits in Female and Male Instructed Courses Mean Responses Based on Standardized Data

\begin{tabular}{|c|c|c|c|c|c|}
\hline \multirow[b]{2}{*}{ Traits } & \multicolumn{2}{|c|}{$\begin{array}{c}\text { Student: Female } \\
\text { Instructor: Female } \\
\mathbf{N}=\mathbf{5 7}\end{array}$} & \multicolumn{2}{|c|}{$\begin{array}{c}\text { Student: Female } \\
\text { Instructor: Male } \\
\qquad \mathbf{N}=\mathbf{1 0 1}\end{array}$} & \multirow[b]{2}{*}{ p-value } \\
\hline & Mean & Variance & Mean & Variance & \\
\hline Class preparedness & 0.77248 & 0.18566 & 0.42982 & 0.64241 & 0.00062 \\
\hline Relaxed demeanor & -0.71139 & 1.12032 & -0.00822 & 0.78290 & 0.00004 \\
\hline Outgoing personality & -0.34613 & 0.75537 & 0.04331 & 0.77653 & 0.00790 \\
\hline Encouraging & 0.04196 & 0.91662 & 0.37829 & 0.65515 & 0.02658 \\
\hline Fair & 0.29307 & 0.91450 & 0.61019 & 0.42012 & 0.02711 \\
\hline Enthusiastic & 0.04196 & 0.85615 & 0.35252 & 0.55792 & 0.03177 \\
\hline Repetitive (content/concepts) & -0.84836 & 0.94527 & -0.49779 & 1.06689 & 0.03493 \\
\hline Caring attitude & 0.13327 & 0.77128 & 0.39117 & 0.68634 & 0.07239 \\
\hline Rank/title & -1.44190 & 1.27733 & -1.11620 & 1.36630 & 0.08776 \\
\hline Established research record & -1.12230 & 0.72248 & -0.87141 & 1.21810 & 0.11269 \\
\hline Rigorous & -0.87119 & 1.01317 & -0.63951 & 0.85733 & 0.15484 \\
\hline Receptive to questions & 0.27024 & 0.73309 & 0.44270 & 0.46907 & 0.19434 \\
\hline
\end{tabular}

Average responses from female students reflected statistically significant differences $(p<0.05)$ when comparing female instructors and male instructors in six other traits. In each of these six traits, female students reported the trait contributed less to good teaching for female instructors than for male instructors. A "relaxed demeanor" was seen as less effective for female instructors (mean standardized response $=-0.77139$ ) than for male instructors (mean standardized response $=-0.00822$ ). An "outgoing personality" was viewed as a below average trait for female instructors (mean standardized response $=-0.34613$ ) but as a slightly above average trait for male instructors (mean standardized response $=0.04331$ ). An instructor who was viewed as "encouraging" was more likely to be seen as a better teacher. Female survey respondents scored this trait as average (mean standardized response $=0.04196$ ) for female instructors and above average (mean standardized response $=0.37829$ ) for male instructors. A trait of "fairness" was seen as contributing more for male instructors (mean standardized response = 0.61019) than for female instructors (mean standardized response $=0.29307$ ). "Enthusiasm" reflected a greater contribution to good teaching for male instructors (mean standardized response $=0.35252$ ) than for female instructors (mean standardized response $=0.04196$ ). Repetition of content or concepts was perceived as a negative contribution to good teaching and perceived more negatively when female instructors repeated content or concepts (mean standardized response $=-0.84836$ ) than when male instructors demonstrated similar behavior (mean standardized response $=-0.49779$ ).

Two traits reflected differences at a lower level of statistical significance $(\mathrm{p}<0.10)$. A "caring attitude" was viewed as contributing more than average to good teaching, but a caring attitude from a male instructor was seen as a greater contribution (mean standardized response $=0.39117$ ) than when a female instructor presented a caring attitude (mean standardized response $=0.13327$ ). Female students did not appear to be impressed with instructor rank or titles, and even less so with female instructors (mean standardized response $=-1.44190$ ) than with male instructors (mean standardized response $=-1.11620$ ).

Three traits reflected differences at a marginal level of statistical significance (p-value <0.20). An "established research record" and "academic rigor" were perceived by female students as contributing less than an average trait to good teaching. In each case, traits demonstrated by female instructors reflected lower average responses than were traits for male instructors. An established research record was seen as a below average trait for both female instructors (mean standardized response $=-1.12230$ ) and male instructors (mean standardized response $=-0.87141$ ). Academic rigor was perceived by female students as a below average teaching trait; average responses in classes taught by female instructors were lower (mean standardized response $=-0.87119$ ) than the response reflected in classes taught by male instructors (mean standardized response $=-0.63591$ ). An instructor's "receptiveness to questions" was viewed as an above average trait, but the trait was perceived more favorably when demonstrated by a male instructor (mean standardized response $=0.44270$ ) than when demonstrated by a female instructor (mean standardized response $=0.27024$ ). 


\section{Male Student Responses Across Courses}

Of the 223 male students responding to the survey, 55 ranked the traits while enrolled in a course taught by a female instructor, while 168 completed the survey in a class taught by a male instructor. Nine traits reflected statistically significant differences when comparing responses by male students for a class taught by a female instructor versus a male instructor. These traits and the mean standardized responses for each group are reported in Table 4. For four of those teaching traits (content/subject matter expertise, organized presentation, engaging, and industry experience), the mean responses were higher in the classes taught by female instructors when compared to mean responses in classes taught by male instructors.

Table 4

Male Student Comparisons of Traits in Female and Male Instructed Courses Mean Responses Based on Standardized Data

\begin{tabular}{|c|c|c|c|c|c|}
\hline \multirow[b]{2}{*}{ Traits } & \multicolumn{2}{|c|}{$\begin{array}{c}\text { Student: Male } \\
\text { Instructor: Female } \\
\mathbf{N}=\mathbf{5 5}\end{array}$} & \multicolumn{2}{|c|}{$\begin{array}{c}\text { Student: Male } \\
\text { Instructor: Male } \\
\mathbf{N}=\mathbf{1 6 8}\end{array}$} & \multirow[b]{2}{*}{ p-value } \\
\hline & Mean & Variance & Mean & Variance & \\
\hline Content/subject matter expertise & 0.78332 & 0.25864 & 0.57786 & 0.42625 & 0.01656 \\
\hline Relaxed demeanor & -0.24743 & 0.96937 & 0.00794 & 0.67742 & 0.08409 \\
\hline Organized presentation & 0.39393 & 0.52156 & 0.21041 & 0.72205 & 0.11941 \\
\hline Engaging & 0.34812 & 0.69470 & 0.15042 & 0.63788 & 0.12439 \\
\hline Outgoing personality & -0.20162 & 0.96937 & 0.03044 & 0.90398 & 0.12746 \\
\hline Strict adherence to course materials & -1.02622 & 1.13823 & -0.77194 & 1.28566 & 0.13241 \\
\hline Work (industry) experience & 0.32521 & 0.75027 & 0.13542 & 0.76301 & 0.16069 \\
\hline Receptive to questions & 0.23359 & 0.60920 & 0.39788 & 0.55116 & 0.17172 \\
\hline Sense of Humor & 0.02744 & 0.96403 & 0.22541 & 0.97481 & 0.19629 \\
\hline
\end{tabular}

Male respondents rated "content/subject matter expertise" as contributing to good teaching higher than average. Males respondents rated this trait higher $(\mathrm{p}$-value $=0.01656)$ in classes taught by female instructors (mean standardized response $=0.78332$ ) than they did in classes taught by male instructors (mean standardized response $=$ 0.57786). Male students rated a "relaxed demeanor" as an average trait in classes taught by male instructors (mean standardized response $=0.00794$ ), but as a below average trait in classes taught by female instructors (mean standardized response $=-.024743$ ). "Organized presentations" and "engaging" behavior reflected higher ratings in classes taught by female instructors than in classes taught by male instructors. In contrast, female students did not reflect statistically significant differences between the two environments for these two traits.

Much like the female respondents to the survey, male respondents rated an "outgoing personality" as a below average good teaching trait (mean standardized response $=-0.20162$ ) in classes taught by female instructors and as an average teaching trait (mean standardized response $=0.03044$ ) in classes taught by male instructors.

"Strict adherence to course materials" was viewed as contributing less to good teaching in classes taught by female instructors (mean standardized response $=-1.02622$ ) than in classes taught by male instructors (mean standardized response $=-0.77194$ ). Male respondents identified "work (industry) experience" as a trait contributing slightly more than average to good teaching for female instructors (mean standardized response $=0.32521$ ) than male instructors (mean standardized response $=0.13542$ ). The difference between these two sets of responses was statistically significant at a low level of confidence $(\mathrm{p}$-value $<0.20)$.

Male respondents viewed "receptive to questions" as a trait slightly above average but rated male instructors more positively on this trait (mean standardized response $=0.39788$ ) than they rated female instructors (mean standardized response $=0.23359$ ). "A sense of humor" was viewed more positively by male respondents for male instructors (mean standardized response $=0.22541$ ) than for female instructors (mean standardized response $=$ $0.02744)$.

This analysis examined survey responses across courses and illustrates that male and female students do indeed have different ideas about traits that contribute to effective teaching. Furthermore, female students view 
traits that make female teachers effective somewhat differently than traits that make male teachers effective. The same is true for male students.

\section{Female and Male Responses Within Courses}

While the previous analysis examined survey responses across courses, the analysis in this section looks at survey responses within courses. Specifically, at issue was whether there is a difference between survey responses from female and male respondents within courses taught by female instructors and within courses taught by male instructors. The top portion of Table 5 reflects the mean standardized responses for those teaching traits for which female and male respondents rated the traits differently in classes taught be female instructors. Six traits reflected statistically significant differences. For two of those traits, "class preparedness" and "professional attire," female respondents rated these traits higher than did male respondents. Female respondents rated a "relaxed demeanor" in a class taught by a female instructor much lower (mean standardized response $=-0.71139$ ) than did male respondents in the same class (mean standardized response $=-0.24743$ ). The difference between these mean responses was statistically significant ( $\mathrm{p}$-value $=0.01794)$. "Class preparedness" was rated as contributing more to good teaching by female respondents (mean standardized response $=0.77248$ ) than by male respondents (mean standardized response $=0.50846)$. The difference was statistically significant $(\mathrm{p}$-value $=0.02018)$.

Male respondents rated "professional attire" in classes taught by female instructors as contributing less to good teaching (mean standardized response $=-1.02622$ ) than did female respondents in the same classes (mean standardized response $=-0.73422$ ). The difference between these mean responses was less significant than other traits ( $\mathrm{p}$-value $=0.19036)$. An established research record by a female instructor was scored as contributing less than average by female respondents (mean standardized response $=-1.12230$ ) and by male respondents (mean standardized response $=-0.79716$ ). The difference between the responses of the two groups in courses taught by female instructors was statistically significant at an intermediate level ( $\mathrm{p}$-value $<0.10)$.

Table 5

Female and Male Student Comparisons of Traits

Mean Responses Based on Standardized Data

Responses From Classes Taught By Female Instructors

\begin{tabular}{|c|c|c|c|c|c|}
\hline \multirow[b]{2}{*}{ Traits } & \multicolumn{2}{|c|}{$\begin{array}{c}\text { Student: Female } \\
\text { Instructor: Female } \\
\mathbf{N}=\mathbf{5 7}\end{array}$} & \multicolumn{2}{|c|}{$\begin{array}{c}\text { Student: Male } \\
\text { Instructor: Female } \\
\mathbf{N}=\mathbf{5 5}\end{array}$} & \multirow[b]{2}{*}{ p-value } \\
\hline & Mean & Variance & Mean & Variance & \\
\hline Class preparedness & 0.77248 & 0.18566 & 0.50846 & 0.51087 & 0.02018 \\
\hline Professional attire & -0.73422 & 1.37600 & -1.02622 & 1.37336 & 0.19036 \\
\hline Relaxed demeanor & -0.71139 & 1.12032 & -0.24743 & 0.96937 & 0.01794 \\
\hline Established research record & -1.12230 & 0.72248 & -0.79716 & 0.92983 & 0.06133 \\
\hline Rigorous & -0.87119 & 1.01317 & -0.56811 & 1.08480 & 0.12042 \\
\hline Educational credentials & -0.39179 & 0.87631 & -0.13290 & 1.16709 & 0.17872 \\
\hline \multicolumn{6}{|c|}{ Responses From Classes Taught By Male Instructors } \\
\hline & \multicolumn{2}{|c|}{$\begin{array}{c}\text { Student: Female } \\
\text { Instructor: Male } \\
\qquad \mathbf{N}=101\end{array}$} & \multicolumn{2}{|c|}{$\begin{array}{c}\text { Student: Male } \\
\text { Instructor: Male } \\
\mathbf{N}=\mathbf{1 6 8}\end{array}$} & \\
\hline Traits & Mean & Variance & Mean & Variance & p-value \\
\hline Encouraging & 0.37829 & 0.65515 & 0.12792 & 0.81590 & 0.01947 \\
\hline Experienced lecturer & -0.08552 & 0.93478 & 0.12043 & 0.84967 & 0.08633 \\
\hline Responsive & 0.39117 & 0.48315 & 0.24041 & 0.63788 & 0.10480 \\
\hline Fair & 0.61019 & 0.42012 & 0.46537 & 0.66164 & 0.10874 \\
\hline Educational credentials & -0.54933 & 1.22011 & -0.32951 & 1.14836 & 0.11116 \\
\hline High academic standards & -0.02110 & 0.70746 & -0.18703 & 0.92044 & 0.13871 \\
\hline Sense of Humor & 0.04331 & 0.97971 & 0.22541 & 0.97481 & 0.14478 \\
\hline Enthusiastic & 0.35252 & 0.55792 & 0.21041 & 0.70305 & 0.15041 \\
\hline Clear presentations & 0.36540 & 0.65750 & 0.21791 & 0.66792 & 0.15094 \\
\hline Respectful & 0.49424 & 0.55121 & 0.36789 & 0.62583 & 0.18846 \\
\hline
\end{tabular}


"Rigorous" female instructors were viewed less favorably by female respondents (mean standardized response $=-.87119$ ) than by male respondents (mean standardized response $=-0.56811$ ). Female respondents viewed "educational credentials" of female instructors less favorably (mean standardized response $=-0.39179$ ) than did male respondents (mean standardized response $=-0.13290$ ).

Comparing the responses from classes taught by female instructors versus male instructors in Table 5, male instructors appear to have been rated slightly more positively than their female counterparts. Whereas responses in classes led by female instructors reflected student responses below the average responses, responses in classes led by male instructors reflected more responses above the overall average. "Encouraging" male instructors were scored above average by both female respondents (mean standardized response $=0.37829$ ) and male respondents (mean standardized response $=0.12792)$. The difference was statistically significant ( $\mathrm{p}$-value $<0.02)$. Female respondents viewed an "experienced lecturer" below average (mean standardized response $=-0.08552$ ); male respondents rated this trait above the average (mean standardized response $=0.12043$ ). The difference was statistically significant.

Female respondents scored male instructors more positively than did male respondents on such traits as "responsiveness," "fair," "enthusiastic," "clear presentation," and "respectful." Male respondents viewed traits such as "educational credentials," "high academic standards," and "sense of humor" more positively than did female respondents.

\section{CONCLUSION AND DISCUSSION}

Prior to summarizing the findings, it is important to acknowledge the limitations of this study. This study focused on data gathered from both undergraduate and graduate students at one public Midwestern university business school. In total, 381 survey responses were analyzed. While it is possible that the data collected would be consistent with other student populations at other institutions across the country, caution is advised in making generalizations as with any research done on a particular population. Data collected from business students in the Midwest may provide different results than data collected from business students in other parts of the country or the world, and business students may have different opinions than students studying other disciplines. However, the study has important implications.

While the proportion of male and female students at the business school where this study was done is essentially the same in 2012 as it was in 1992, the characteristics of the students within the group have likely changed in terms of their attitudes toward technology and society, their communication styles, their preferred learning styles, and their perceptions of the world around them. This study is essentially designed to measure perception, and different students believe that different characteristics of faculty members make the individual a more effective teacher. The goal of the research was to determine if student perceptions of teaching effectiveness differ by gender, and the results suggest that they do. Female students believe that 29 of the 35 traits studied contribute more to good teaching than male students believe they do. Of those 29 traits that female students rated more highlight than male students, 22 showed statistically significant differences in means between male and female student responses.

Further analysis revealed that female students perceive teaching effectiveness differently when taking classes from a female instructor versus a male instructor. Female students rated female instructors higher than their male counterparts for only one of the 12 traits, class preparedness. Female students thought the remaining 11 traits with statistically significant differences between female and male instructor ratings each contributed more to good teaching for male instructors than for female instructors. These 11 traits are the following: relaxed demeanor, outgoing personality, encouraging, fairness, enthusiasm, repetition of content/concepts, caring attitude, instructor rank/titles, established research record, academic rigor, and receptiveness to questions. One of the most interesting findings of this research is that characteristics that were found to be significant predictors (such as a faculty member's research record or her instructor rank/title) have little or no impact on the faculty member's teaching ability. However, these characteristics impact the student's perception of the faculty member and, therefore, the effectiveness of the faculty member to convey knowledge to that particular student. 
Nine traits reflected statistically significant differences when comparing responses by male students for a class taught by a female instructor versus a male instructor. Male students rated female instructors higher than their male counterparts for four of the nine traits (content/subject matter expertise, organized presentation, engaging, and industry experience). Male students rated male instructors higher than female instructors for the remaining five traits including relaxed demeanor, outgoing personality, strict adherence to course materials, receptiveness to questions, and sense of humor. Again, the theme of differences in perception based on student gender and instructor gender is reinforced. These findings also suggest that there are many factors that impact teaching effectiveness that are not under the immediate control of the faculty member in the short term. For example, male students believe that industry experience contributes to teaching effectiveness for female instructors. This suggests that female business instructors with industry experience should make the students aware of that experience, but female faculty members who lack industry experience may not be able to impact that particular characteristic in the short term. On the other hand, these results also suggest that there are many factors that contributed to teaching effectiveness that are under the direct control of the faculty member such as making organized presentations, adhering to course materials, and being receptive to questions.

In addition to analyzing survey responses across courses, responses were also analyzed within courses. Six traits showed statistically significant differences for female versus male student ratings of female instructors in the same class. For courses taught by female instructors, female students believe that two traits (class preparedness and professional attire) contribute more to effective teaching than male students believe they do. Interestingly, both of these traits are under the direct control of the faculty member, which is good news when it comes to improving teaching effectiveness. Male students believe that four different traits (relaxed demeanor, established research record, rigor, and educational credentials) contribute more to effective teaching by female instructors than female students do. The first three traits are things that the faculty member can control in the short term. While a faculty member can certainly seek more educational credentials, it may be a challenging pursuit while working full-time. Therefore, the fourth trait may be more difficult to impact in the near term.

Ten traits reflected statistically significant differences for female versus male student ratings of male instructors. For courses taught be male instructors, female students believed six traits (encouraging, responsive, fair, enthusiastic, clear presentation, and respectful) contribute more to effective teaching than male students believe they do. Male students believe four different traits (experienced lecturer, educational credentials, high academic standards, and sense of humor) contribute more to effective teaching than female students appear to believe. Interestingly, many of the traits that female students believe contribute to teaching effectiveness are characteristics that the instructor can strive to improve.

The findings of this study suggest that there are differences between female and male business student ratings of teacher effectiveness. Females in general tend to rate teachers higher in terms of contributions to teaching effectiveness. Furthermore, there are specific traits which appear to be more important to females, and other specific traits which appear to be more important to males. This study provides strong evidence that there are systematic differences between male and female students in terms of what teaching traits each finds important and how they rate instructors of each gender.

Given that college classrooms today tend to have a mix of male and female students, it is likely not possible for a faculty member to cater to one gender over the other. However, if one gender does dominant a particular class, this study may suggest that modification of the instructor's behavior may prove beneficial at least when it comes to student evaluations. For example, faculty members might ask students to complete a learning styles inventory at the beginning of the semester, and the data from that inventory could help the faculty member to tailor his or her teaching style to the students in the particular class that semester. Yet it is important that faculty members and especially administrators are aware of the potential for gender bias in ratings of teacher effectiveness. Men and women are different. Therefore, it is important that faculty members use multiple methods of teaching in their classes and also offer multiple methods of knowledge assessment within a course. Male and female students are different, and they perceive differences between male and female faculty members. 


\section{AUTHOR INFORMATION}

Leon Korte earned his Ph.D. at the University of Nebraska, Lincoln in 1992. Currently he is an associate professor of accounting at the University of South Dakota. Contact at: Leon Korte, Ph.D., Beacom School of Business, University of South Dakota, 414 E. Clark Street, Vermillion, SD 57069 USA. E-mail: Leon.Korte@ usd.edu

Angeline M. Lavin earned her Ph.D. at the University of Nebraska, Lincoln in 1997. Currently she is a professor of finance at the University of South Dakota where she also serves as the Graduate Business Programs Director. Contact at: Angeline Lavin, Ph.D., Beacom School of Business, University of South Dakota, 414 E. Clark Street, Vermillion, SD 57069 USA. E-mail: Angeline.Lavin@usd.edu (Corresponding author)

Thomas L. Davies earned his LL.M. in Tax at the University of Missouri, Kansas City in 1992. Currently he is a professor of accounting at the University of South Dakota where he also serves as the Associate Dean of the Beacom School of Business. Contact at: Thomas Davies, L.L.M., Beacom School of Business, University of South Dakota, 414 E. Clark Street, Vermillion, SD 57069 USA. E-mail: Thomas.Davies@usd.edu

\section{REFERENCES}

1. Bachen, C. M., McLoughlin, M. M., \& Garcia, S. S. (1999). Assessing the role of gender in college students' evaluations of faculty. Communication Education, 48, 193-210.

2. Basow, S. A. (1995). Student evaluations of college professors: When gender matters. Journal of Educational Psychology, 87(4), 656-665.

3. Basow, S. A. (2000). Best and worst professors: Gender patterns in students' choices. Sex Roles: A Journal of Research, 34, 407-417.

4. Centra, J., \& Gaubatz, N. (2000). Is there gender bias in student evaluations of teaching? Journal of Higher Education, 71, 17-33.

5. Feldman, K. A. (1993). College students' views of male and female college teacher: Part II-Evidence from students' evaluations of their classroom teachers. Research in Higher Education, 34, 151-211.

6. Fernandez, J., \& Mateo, M. (1997). Student and faculty gender in ratings of university teaching quality. Sex Roles, 37, 997-1003.

7. Lavin, A., Korte, L., \& Davies, T. (2012). Student gender and perceptions of teaching effectiveness. Research in Higher Education, 18, 1-16.

8. McKeachie, W. J. (1990). Research on college teaching: The historical background. Journal of Educational Psychology, 82(2), 189-200.

9. Sprague, J., \& Massoni, K. (2005). Student evaluations and gendered expectations: What we can't count can hurt us. Sex Roles, 53, 779-93.

10. Sprinkle, J. D. (2008). Student perceptions of effectiveness: An examination of the influence of student bias. College Student Journal, 42(2), 276-293.

11. Tatro, C. N. (1995). Gender effects on student evaluations of faculty. Journal of Research and Development in Education, 28 (3), 169-173.

12. Young, S., Rush, L., \& Shaw, D. (2009). Evaluating gender bias in ratings of university instructors' teaching effectiveness. International Journal for the Scholarship of Teaching and Learning, 3(2), 1-14. Retrieved from http://academics.georgiasouthern.edu/ijsotl/v3n2/articles/ YoungRushShaw/index.htm

13. Zhang, L. F. (2004). Thinking styles: University students' preferred teaching styles and their conceptions of effective teachers. The Journal of Psychology, 138 (3), 233-252. 